\title{
BMJ Open Using the Consumer Experience with Pharmacy Services Survey as a quality metric for ambulatory care pharmacies: older adults' perspectives
}

\author{
Olayinka O Shiyanbola, ${ }^{1}$ David A Mott, ${ }^{1}$ Kenneth D Croes ${ }^{2}$
}

To cite: Shiyanbola 00 , Mott DA, Croes KD. Using the Consumer Experience with Pharmacy Services Survey as a quality metric for ambulatory care pharmacies: older adults' perspectives. BMJ Open 2016;6:e011241. doi:10.1136/bmjopen-2016011241

- Prepublication history for this paper is available online. To view these files please visit the journal online (http://dx.doi.org/10.1136/ bmjopen-2016-011241).

Received 22 January 2016 Revised 27 April 2016 Accepted 3 May 2016

CrossMark

\footnotetext{
${ }^{1}$ Division of Social and Administrative Sciences, University of WisconsinMadison, Madison, Wisconsin, USA

2University of Wisconsin Survey Center, University of Wisconsin-Madison, Madison, Wisconsin, USA

\section{Correspondece to} Dr Olayinka 0 Shiyanbola; Olayinka.Shiyanbola@wisc. edu
}

\section{ABSTRACT}

Objectives: To describe older adults' perceptions of evaluating and comparing pharmacies based on the Consumer Experience with Pharmacy Services Survey (CEPSS), describe older adults' perceived importance of the CEPSS and its specific domains, and explore older adults' perceptions of the influence of specific CEPSS domains in choosing/switching pharmacies.

Design: Focus group methodology was combined with the administration of a questionnaire. The focus groups explored participants' perceived importance of the CEPSS and their perception of using the CEPSS to choose and/or switch pharmacies. Then, using the questionnaire, participants rated their perceived importance of each CEPSS domain in evaluating a pharmacy, and the likelihood of using CEPSS to switch pharmacies if their current pharmacy had low ratings. Descriptive and thematic analyses were done.

Setting: 6 semistructured focus groups were conducted in a private meeting room in a Mid-Western state in the USA.

Participants: 60 English-speaking adults who were at least 65 years, and had filled a prescription at a retail pharmacy within 90 days.

Results: During the focus groups, the older adults perceived the CEPSS to have advantages and disadvantages in evaluating and comparing pharmacies. Older adults thought the CEPSS was important in choosing the best pharmacies and avoiding the worst pharmacies. The perceived influence of the CEPSS in switching pharmacies varied depending on the older adult's personal experience or trust of other consumers' experience. Questionnaire results showed that participants perceived health/ medication-focused communication as very important or extremely important $(n=47,82.5 \%)$ in evaluating pharmacies and would be extremely likely $(n=21$, $36.8 \%$ ) to switch pharmacies if their pharmacy had low ratings in this domain.

Conclusions: The older adults in this study are interested in using patient experiences as a quality metric for avoiding the worst pharmacies. Pharmacists' communication about health and medicines is perceived important and likely to influence older adults' pharmacy selection.

\section{Strengths and limitations of this study}

- For the first time, research examines older adults' perceptions of pharmacy patient experience measures, which is important as pharmacy quality organisations aim to include patient experiences as part of a pharmacy's quality metrics.

- This is the only study to examine whether older adults perceive patient experience measures (that may be publicised in pharmacy quality reports) as important or useful in their healthcare provider selection.

- This study is significant in improving the quality of care provided by pharmacy providers as the pharmacy profession moves towards the development of quality ratings that can be understood and used by patients to inform their pharmacy selection.

- Limited geographical area.

- Convenience sample.

\section{BACKGROUND}

Public reporting of quality of care information has been suggested as a means for patients to actively choose best performing providers that deliver quality and efficient care. ${ }^{1}$ With access to provider performance data, it is assumed that patients are aware of the differences in quality of care and can make an informed decision based on this information. $^{2}$ It is expected that when patients become selective of their healthcare providers based on publicly available performance information, providers will be forced to improve quality of care, so that they can maintain their reputation and stay competitive. ${ }^{3}$

Although work has been done to encourage patients to utilise provider performance information to choose their healthcare providers, it is disconcerting to know that available public reports are not commonly used by 
patients, and the public reports do not have a substantial effect on patients' decision-making. ${ }^{2}{ }^{4}$ This is due to a myriad of factors, including a lack of awareness of available provider performance information and low perceived usefulness of the information. ${ }^{35-7}$ In addition, it is reported that patients do not have an interest in using provider performance information because the information presented is irrelevant and contains provider performance measures that are not understandable. ${ }^{89}$

As it relates to pharmacy choice, our previous studies showed that patients do not understand the meaning and interpretation of pharmacy performance measures and few individuals are likely to use them to make an informed pharmacy choice. ${ }^{810}{ }^{11}$ It has been suggested that one way to get patients to use quality information in guiding their provider choice is to consider the features of quality that patients care about and that patients believe are relevant to their choice. ${ }^{12} 13$

Patient care experience measures are increasingly used in public reporting to highlight the patient's perspective of their care. ${ }^{14}$ Standardised patient surveys such as the Consumer Assessment of Healthcare Providers and Systems (CAHPS) survey is a mechanism through which the information and experiences that patients gain while using health services can be captured and summarised. ${ }^{15}$ Although data describing patients' healthcare experiences might be used by consumers to choose better performing providers (eg, hospitals) as well as hold them accountable ${ }^{16}$ no one facilitated the development of patient care experience surveys for the care provided in ambulatory (outpatient) pharmacies until recently. A standardised survey, the Consumer Experience with Pharmacy Services Survey (CEPSS), has been developed for patients' evaluation of pharmacy services received in an ambulatory care setting. ${ }^{15} 17$

The CEPSS was developed as a mechanism for benchmarking the quality of pharmacy services provided by pharmacists nationwide. Most patients use a pharmacy for ambulatory care services such as filling a prescription medication, obtaining medication information about an overcounter drug, or getting advice about disease selfmanagement. ${ }^{15}$ With the CEPSS, the information relevant to pharmacy quality based on patients' interactions with pharmacists can be captured from survey responses. Based on the CAHPS initiative, the CEPSS is a reliable and valid survey to capture patient perceptions of pharmacy quality. There are four measures of pharmacy quality within the CEPSS: pharmacy staff communication, health-focused and medication-focused communication, pharmacy care, and clarity of written information about medicines (table 1). Similar to the CAHPS survey, the rationale for the CEPSS is that it can be used by healthcare organisations, insurers, and patients as a quality metric in evaluating and comparing a pharmacy's performance and ultimately motivate patients to choose high-quality pharmacies. ${ }^{15} 17$

Previous studies have reported mixed results related to the usefulness of the CAHPS survey in patients'
Table 1 The Consumer Experience with Pharmacy Services Survey (CEPSS) ${ }^{\star}$ quality domains

Quality domain Definition†

Pharmacy staff

communication

Pharmacy staff listens carefully, treats you with respect and courtesy, spends time talking to you, shows concern for you, explains things in a way that is easy to understand, talks to you about your health.

Pharmacy care Pharmacist talks to you about how your medicine is supposed to help you, advises you on how to treat a new health problem, talks to you about whether it is safe to take a new prescription medicine along with your regular prescription medicine.

Health and medication-focused communication Pharmacy staff asks if you have problems with your medicine; you can talk to staff about your medicine as often and as soon as you want; when you have a new prescription filled, the staff tells you how often and when to take your medicine, what to avoid when taking your medicine, and what to do when you have bad reactions.

Clarity of written The instruction on your medicine information about medicines label is easy to read and easy to understand; the pharmacy staff gives you written information about the medicine; the information on the medicine is written in a way that is easy to read and easy to understand.

*The Pharmacy Quality Alliance developed a standardised survey that can be used to examine patient assessments of the quality of services they receive during ambulatory care pharmacy encounters. The survey is modelled after similar surveys of physicians and health plans and assesses patient experiences with the key elements of care. The survey focuses on the information flow between pharmacists and patients from the patient's perspective.

†Definitions were provided to the focus group participants.

evaluations of hospitals and health plans, ${ }^{1} 2$ 18-22 and the importance of the CAHPS measures in patient decision-making. ${ }^{1} 2324$ Since the development of the CEPSS, no research has examined whether patient experience information might be useful to patients' evaluations of pharmacies and if the CEPSS is important in patients' decision-making concerning their pharmacy. Also, we do not know if patients' perceptions of the usefulness of the CEPSS are similar to reported usefulness of the CAHPS survey. In our previous study, patients with chronic illnesses who discussed the usefulness of clinical pharmacy quality measures also wanted to see consumer experience quality metrics. ${ }^{11}$ It is assumed that the CEPSS will be important to pharmacy consumers for several reasons. For example, a pharmacist may ensure the accuracy of a prescription medication, check the 
appropriate labelling of a prescription medication, and ensure the safe administration of the medicine by checking for drug interaction. Based on clinical quality metrics, this pharmacy may be ranked as 'high technical quality'. However, the pharmacist may not give the patient the amount of time and attention needed, answer their questions appropriately, or offer private counselling spaces during the discussion of sensitive health issues. These aspects of pharmacy quality can only be evaluated based on patient input and experience. ${ }^{15}$ Hence, the CEPSS can be important as a quality metric in facilitating patients' pharmacy choice.

This study focuses on older adults' perceptions of using the CEPSS to evaluate and compare pharmacies, their perceived importance of the survey, and the perceived influence of the survey in their pharmacy selection. The research is significant to older adults because they use a lot of medicines, are more likely to have a chronic condition and are at risk for preventable adverse drug events. ${ }^{25}$ Owing to these reasons, they are more likely to talk to the pharmacist about their prescription medicines and use pharmacies for medication reviews, disease management and other pharmacy services. ${ }^{26}$ Exploring older adults' perceptions of the CEPSS will allow this information to be used in the development of public reports that will help them identify better performing pharmacies.

According to Hibbard et $a l \mathrm{~s}^{24}$ theoretical consumer choice model, a psychological process takes place in a patient's mind before they proceed with a behaviour (ie, provider decision-making using quality information). Specifically, the model proposes that patients need to be aware of the availability of quality information, trust the information and perceive the information as useful to them (the psychological processes) before it can be used in their decision-making (the behaviour). ${ }^{25} 24$ This study explores, in part, these psychological processes among older adults who could potentially use pharmacy quality information.

\section{OBJECTIVES}

The objectives of the study are to (1): describe older adults' perceptions of evaluating and comparing pharmacies based on the CEPSS; (2) describe older adults' perceived importance of the CEPSS and its specific domains and (3) explore older adults' perceptions of the influence of specific CEPSS domains in choosing/ switching pharmacies.

\section{METHODS}

\section{Sample}

The convenience sample for this study consisted of English-speaking individuals who had filled a prescription at a retail pharmacy within 90 days of recruitment and who were at least 65 years of age. The authors partnered with staff at senior apartment facilities and community centres to recruit participants by means of email announcements, word of mouth and flyers. Participants were informed of the study's eligibility criteria, objectives and compensation for participating $(\$ 50$ cash $)$. Recruiters enlisted the participation of men and women who had the capacity and ability to provide consent. Based on the number of participants who responded to the recruitment efforts, 60 people were recruited to six focus groups. There were no drop-outs or refusals to participate.

\section{Study design and data collection}

Using a phenomenology approach, focus groups were chosen as the data collection method because the ways in which older adults think about and might use pharmacy patient experience measures are insufficiently understood. Focus groups allowed for gathering and exploring a wide range of perspectives on pharmacy quality. A semistructured questioning route was developed by the authors and used at all six groups. The focus group guide was not pilot-tested prior to the start of the study. The participants were informed of the reasons for conducting the research and the reason for the investigators' interest in the research topic. One of the authors (KDC), a trained male focus group moderator and a PhD-trained cultural anthropologist, who has 20+ years of experience conducting qualitative research, facilitated the groups. All groups were attended by the study's principal investigator (OOS). Field notes were taken by OOS during the focus groups and discussed with the moderator. Senior apartment facilities and community centres in Madison, Wisconsin, USA, served as venues for the groups. The groups took place from May to July 2014 and lasted $\sim 90 \mathrm{~min}$ each. Participants were not given any information about CEPSS before completing the focus groups.

To explore the triangulation of results, a brief $10 \mathrm{~min}$, 12-item questionnaire was self-administered at the end of the focus groups. The questionnaire asked participants to rate the importance of each specific CEPSS domain in evaluating pharmacies (on a five-point Likert scale, response options were 'not at all important' to 'extremely important'. Also, on a five-point Likert scale, participants indicated their likelihood of changing pharmacies if a pharmacy rated low in a specific domain (response options were 'not at all likely' to 'extremely likely'). Participants' demographic information was also collected.

\section{Analysis}

The analysis in this article focuses on the following questions, which are a subset of questions administered at the focus groups:

- I will ask you to imagine that you had access to a report that compares pharmacies based on all the aspects of pharmacy quality that we have been talking about (the following measures of pharmacy quality, including their definitions, which had been discussed individually, were displayed on a flipchart to facilitate 
participant discussion of the present question: health and medication-related communication, pharmacy staff communication, pharmacy care, clarity of written information provided with medications; see table 1 for descriptions). Imagine that the report would tell you which pharmacies do better and which do worse on these aspects of pharmacy quality. What would you think about pharmacies being evaluated and compared on these aspects?

- What would you do if you read such a report and saw low-quality ratings for your pharmacy?

- Which aspect of pharmacy quality, if you found it rated low in a report, would prompt you to change your pharmacy? What is important to you about this factor?

- What are your thoughts on how to distribute a report on pharmacy quality to pharmacy customers?

The focus groups were audio recorded, transcribed verbatim by a certified transcriptionist, and independently coded by two of the authors (OOS and KDC). NVivo V.10 (QSR International, Burlington, Massachusetts, USA) was used to organise the data and to categorise the themes. Data saturation was discussed by OOS and KDC. Transcripts were not returned to participants for comments or corrections. The authors used descriptive coding, which is a method of coding qualitative data whereby words or short phrases are assigned to segments of text to capture their essential ideas, and to enable comparison of similar ideas across the entire qualitative data set (in our case, across all transcripts). ${ }^{27}$ The authors coded all transcripts independently and discussed coding divergences. They reached agreement on the application of all codes. All themes were derived from the data and were not identified in advance. The participants did not provide feedback on the findings.

Descriptive statistics were used to examine participant responses to the questionnaire including questions on perceived importance of each CEPSS quality domain and participants' likelihood of changing pharmacies if their pharmacy rated low in a specific CEPSS domain. The questionnaire responses were analysed using SPSS V. 21.0.

\section{RESULTS}

There were 60 older adults in this study. Participants' ages ranged from 65 to 88 years old. At least 8 participants with a maximum number of 12 participants were included in each focus group. The composition of each focus group is published elsewhere. ${ }^{13}$ The highest proportion of older adults were female, white, had a graduate degree and self-reported having good health (table 2). Based on the study objectives, four major themes emerged from the focus group.

First, older adults' perceived the CEPSS to have certain advantages and disadvantages in evaluating and comparing pharmacies. Second, older adults thought the CEPSS was important in choosing the best

\begin{tabular}{|c|c|c|}
\hline Variable & Number (\%) & Mean \pm SD \\
\hline \multicolumn{3}{|l|}{ Sociodemographics } \\
\hline Age & & $73.94 \pm 6.41$ \\
\hline \multicolumn{3}{|l|}{ Gender } \\
\hline Male & $11(19.3)$ & \\
\hline Female & $44(77.2)$ & \\
\hline \multicolumn{3}{|l|}{ Ethnicity } \\
\hline Hispanic & $4(7.0)$ & \\
\hline Non-Hispanic & $50(87.7)$ & \\
\hline \multicolumn{3}{|l|}{ Racial background } \\
\hline White Caucasian & $27(47.4)$ & \\
\hline Black or African-American & $20(35.1)$ & \\
\hline Asian & $2(3.5)$ & \\
\hline Mixed race & $5(8.8)$ & \\
\hline \multicolumn{3}{|l|}{ Years of school completed } \\
\hline 8 grades or less & 0 & \\
\hline Some high school & $4(7.0)$ & \\
\hline High school graduate or GED & $9(15.8)$ & \\
\hline Some college & $16(28.1)$ & \\
\hline College graduate & $8(14.0)$ & \\
\hline Graduate degree & $17(29.8)$ & \\
\hline \multicolumn{3}{|c|}{ Health insurance plan in the past 6 months } \\
\hline An individual plan & $2(3.5)$ & \\
\hline A plan through your employer & $2(3.5)$ & \\
\hline Military or VA Health Plan & $1(1.8)$ & \\
\hline Medicaid & $6(10.5)$ & \\
\hline Medicare & $12(21.1)$ & \\
\hline $\begin{array}{l}\text { More than one type of health } \\
\text { insurance }\end{array}$ & $32(56.1)$ & \\
\hline $\begin{array}{l}\text { I have not had an insurance } \\
\text { plan in the past } 6 \text { months }\end{array}$ & $2(3.5)$ & \\
\hline \multicolumn{3}{|l|}{ Clinical characteristics } \\
\hline \multicolumn{3}{|l|}{ Self-rated health } \\
\hline Excellent & $3(5.3)$ & \\
\hline Very good & $18(31.6)$ & \\
\hline Good & $25(43.9)$ & \\
\hline Fair & $10(17.5)$ & \\
\hline Poor & 0 & \\
\hline $\begin{array}{l}\text { Number of prescription } \\
\text { medications taken daily }\end{array}$ & & $5.55 \pm 3.40$ \\
\hline 1 & $6(10.71)$ & \\
\hline$\geq 2$ & $50(89.3)$ & \\
\hline $\begin{array}{l}\text { Number of pharmacies used in } \\
\text { the past } 6 \text { months }\end{array}$ & & $1.26 \pm 0.52$ \\
\hline 1 & $40(71.43)$ & \\
\hline$\geq 2$ & $14(25.0)$ & \\
\hline \multicolumn{3}{|l|}{ Pharmacy type } \\
\hline Chain & $42(73.7)$ & \\
\hline Independent & $10(17.5)$ & \\
\hline Mail order & $1(1.8)$ & \\
\hline Internet & $2(3.5)$ & \\
\hline
\end{tabular}

pharmacies and avoiding the worst pharmacies. Third, older adults perceived the CEPSS would be influential in their decision to choose a pharmacy. Fourth, older adults' perception of the CEPSS influence in switching 
pharmacies varies depending on the individual's personal experience or trust of other consumers' experience. Additional themes are also described.

The study's overall findings are grouped based on the objectives of the study.

Objective 1: The objective was to describe older adults' perceptions of evaluating and comparing pharmacies based on the CEPSS.

Major theme 1: Older adults perceived the CEPSS to have certain advantages and disadvantages in evaluating and comparing pharmacies. Some older adults supported the use of CEPSS to evaluate and compare pharmacies because many health services are compared in the market place and the evaluation would have a salutary effect on pharmacies that were initially rated as low quality (table 3 ).

I think it's very useful. They rate hospitals nationwide. You can go and look up how your hospital rates. I think you should be able to do that for your pharmacy.

Everybody would get better or do the job better knowing somebody is watching over them. I think they would do a better job if they know somebody out there is watching over them and grading them.

Table 3 Older adults' perception of evaluating and comparing pharmacies based on the Consumer Experience with Pharmacy Services Survey (CEPSS)

\section{Perceptions}

Older adults supported the idea of evaluating pharmacies based on the domains

Several older adults pointed out that many services are compared in today's marketplace so pharmacy quality should be compared too

The evaluation and comparison of pharmacies would have a salutary effect on pharmacies that initially rank low

The evaluation and comparison of pharmacies would be more valuable in urban than in rural locations The evaluation of pharmacies should focus on specific, quantifiable indicators of quality (eg, medication safety) and avoid subjective data

Some older adults would rather use price and pharmacy medication safety in evaluating pharmacies than quality information

Some older adults are sceptical about the evaluation of pharmacies based on the domains because it is subjective information based on individual preferences

\section{Sample quotations}

"I think it's important...to us, the consumer. We need this. We need pharmacies to give us this."

"I think they should be evaluated."

"I think it's a great idea, and you know, of comparisons, we do it. As consumers, we should have a right to make comparisons...We go to supermarkets, we make comparisons...And the same thing with pharmacists-service, oral communication, written communications, pharmacy care, we make a comparison. And what it does is, is when people grade these pharmacies...that'll bring them up...I think it's a great idea."

"Just like they do for our health insurance companies-the pharmacies need to be held to that same standard."

"They rate the hospitals and they rate the doctors, who's good and who's bad, so [why not pharmacies?]"

"I think an evaluation would be a good thing. That way, they know where they would need to improve and to just get an idea of what the public, their customers, you know, the relationship, and just to make things better. It'll give them an idea of, This is what the public is looking at, from us."

"We have so many different pharmacies in Madison, we're spoiled. We're not talking about some little rural community...It's a whole different problem...[when] the next pharmacy is fifty miles away. This [reporting of domains] means nothing."

"Well, you know, hospitals are rated and you can read the ratings on the number of people who get infections while in the hospital...the number of people who die in the hospital and that type of thing... because the hospitals are required to provide that information. So what would have to happen is that all of the pharmacies would have to be required to provide certain facts on their outcome of how many people were given the wrong medication, which as far as I'm concerned that's the only important thing they have to rate is how many people are given the wrong medication...Service?...Well...that's subjective...How long you have to wait. How attentive they are to you... That, again, that doesn't kill you."

"As long as they can give me the right medication I don't give a hoot. I go where the price is right and I don't care actually if they have the best price if the pharmacist frowns at me every time...I don't care if they say hurry up and get out of here. I don't care as long as their price is right... as long as they are competent...no errors. None of these [CEPSS domains] are related to the pharmacy giving you the wrong darn pill."

"I think it's difficult because it's very personal, and it depends...some people like or want more information, others don't want as much. I don't want to spend 10 minutes talking every time... about the drug, which our pharmacist is obligated to do, and it's obvious that he's obligated to come over and say, 'Do you have any questions?'...to me that's good, but somebody else might want more information-so I think it'd be difficult to come up with an objective system that takes in individual choices." 
On the other hand, some older adults were not supportive of using the quality domains to evaluate pharmacies because it was not based on quantifiable clinical indicators of quality but based on subjective information.

If you're real unhappy cause you have to wait [in line], go to a different pharmacy! But the only important thing to get out of a pharmacy is the proper medication and the cost and those are the only two things that are life and death, just as in a hospital. The service you get, whether you're going to get an infection, whether you're going to get a pharmacist who has a poor record...those are the important things, whether they make errors and whether their cost is prohibitive.

\section{Additional minor themes were identified:}

Credibility of the quality information was an important consideration in the use of CEPSS as a quality metric for pharmacies. Older adults stated that their trust (credibility) of the quality information would depend on the information source, timeliness of the information, and whether the quality information was based on the CEPSS or other objective quantifiable data. Verbatim statements included:

\section{Credibility of the information}

Who's doing the judging...? Because you get all kinds of commercial interests involved, and public interests involved, and government interests involved.

If they're going to be rated, then we have to look at who's doing the rating. If it's the customer that would be one thing, if it's some outside source that knows what they're looking for but may not have a direct relationship, that's another thing.

\section{Timeliness of the information}

How are you going to have it be accurate by the time it would get in the hands [of patients], because any selfrespecting pharmacist is going to try and fix whatever the problem is.

\section{CEPSS versus objective data}

Subjective information, that's a problem. However, there are certain factual things [that could be included in a quality report]. I had a pediatrician when my children were little...He said, 'I have called every pharmacy in [town name] with the ten prescriptions I most often prescribe. And, they're cheaper here, they're more expensive there.'... The idea that a doctor actually took the time to find out what his patients were having to pay for the same medication from place to place, that was really a fine thing that he did. That's the kind of research that's factual.

Older adults also suggested that a valid and transparent report on pharmacy quality would need to say:
Who's doing the evaluating, what are the actual criteria on which they're being evaluated...It would help you determine whether this report is valid.

What's the standard [used for evaluating]? What does selection mean or what does attention [to customers by pharmacy staff] mean?

Other minor themes: Dissemination of a quality report containing CEPSS information was important to older adults in using the survey domains.

Older adults volunteered some thoughts on how often the quality report should be compiled, including how to structure the report, and means and locations for wide dissemination including the internet, pharmacies, doctors' offices and American Association of Retired Persons (AARP) magazines. Verbatim statements included:

\section{Compilation of quality report}

You would have to do this [report] fairly often [because lower-ranking pharmacies would improve right away].

\section{Structure of quality report}

I think there's two different ways it could be done. You can rate the individual stores or you could rate (Chain Pharmacy A) versus (Chain Pharmacy B), like the whole corporation and I think it would have greater value rating the individual stores but that would be harder to do.

\section{Dissemination location for quality report}

If you can go by the internet and see-at the pharmacy that I go to, for example, I can enter in the webpage and see if they have a good evaluation.

I think a report should be included with your prescription. When you go there to pick it up, the pharmacist should say, 'Here is a report'.

I would love to have my doctors know which pharmacies are really doing well so that when...I'm in the office [and]...they're going to prescribe a new medication, they could say, 'We know that the following three pharmacies not only routinely stock this but are charging a reasonable price for it.' Now, that doesn't say that's where you have to go. But, I'm not having to get to my pharmacy, which is a small one, and suddenly find out that we're going to have to wait a few hours for them to get it to me.

I think, since everybody here gets AARP, that would be a real good way, because everybody usually goes through the magazine here or the book that you get and knowing that they're behind this $100 \%$, which they should be, since they are doing more representation of the older population.

One other way you could get it around is to have in newspapers and on TV that it is available and here is who you contact to get it. If you don't have a computer you can do that by mail and if you do you can request it on the Internet. 
Objective 2: The objective was to describe older adults' perceived importance of the CEPSS and its specific domains.

Major theme 2: Older adults thought the CEPSS was important in choosing the best pharmacies and avoiding the worst pharmacies (table 4).

It rules out the worst case scenarios for you. If you've got eight to pick from, I would go with the top three...I wouldn't do the one that has poor, poor, poor, on the categories so that way at least you can narrow the field down.

While all the CEPSS domains were important, some older adults strongly supported specific domains compared to others-that is, health and medication-focused communication and pharmacy staff communication were both perceived as the most important quality domains. These results are further confirmed in our questionnaire results.

I think medication-related communication is the most important and as [participant name] says it's the main purpose of the pharmacy...Anything else is extra.

I don't count on the pharmacist as the expert about my health. And, if I have a medication-related communication, I might ask the pharmacist but I'm more likely to look it up online or go through My Chart (a secure online service that allows a patient to communicate with their healthcare provider) with my general practitioner. But, being treated with respect by the pharmacy staff is very important.

Objective 3: The objective was to explore older adults' perceptions of the influence of specific CEPSS domains in choosing/switching pharmacies.

Major theme 3: Older adults perceived the CEPSS would be influential in their decision to choose a pharmacy (table 5).

The first one [ pharmacy] that I was going to, to get my prescriptions, it was because of convenience. But then the staff wasn't as friendly and they didn't ask you questions, and then somebody recommended someplace else but it was inconvenient. But it turned out...it was worth the inconvenience, because the staff there was really concerned and I wasn't afraid to ask them questions.

However, some older adults would rather use price and pharmacy medication safety information to choose pharmacies instead of the CEPSS.

As long as they can give me the right medication I don't give a hoot. I go where the price is right and I don't care actually if they have the best price if the pharmacist frowns at me every time...I don't care if they say hurry up and get out of here. I don't care as long as their price is right...as long as they are competent...no errors. None of these [CEPSS domains] are related to the pharmacy giving you the wrong darn pill.
Major theme 4: Older adults' perception of the CEPSS influence in switching pharmacies varies depending on the individual's personal experience or trust of other consumers' experience (table 5).

Some older adults would switch pharmacies because CEPSS information is based on other consumers' experiences. Other older adults would place greater importance on their own personal pharmacy experiences than other consumers' experiences.

I don't think I would change pharmacies if my own personal experience were good in all those areas...and others might've had a bad experience.

When the older adults discussed what specific CEPSS domain would cause them to switch pharmacies if their pharmacy rated low, health and medication-focused communication and pharmacy staff communication were more frequently described as the quality domains that would cause them to switch their pharmacies.

I take 17 different prescriptions. And, if I couldn't depend on them (the pharmacy) to have accurate... information or the actual medication part of it, if I couldn't trust that, then, I guess, I would have to consider changing.

You can ask about anything you want to if you have a good communication with staff. If you don't have a good communication with the staff, I feel like you're lost, absolutely lost. So... If I was missing that, I'd go someplace else.

\section{Questionnaire results-importance of the specific CEPSS} domains and its use in choosing/switching pharmacies

Fifty-seven participants completed a questionnaire. Three participants had missing data. Patients reported that all the CEPSS domains were extremely important in evaluating and comparing pharmacies. The largest percentage of older adults thought pharmacy staff communication $(\mathrm{n}=27,47.4 \%)$ and health/medication-focused communication $(\mathrm{n}=27,47.4 \%)$ were extremely important in evaluating and comparing pharmacies. None of the older adults chose the 'not at all important' response option for any CEPSS domain (figure 1).

Overall, low ratings in all the CEPSS domains were likely to lead to a change in pharmacy. Twenty-one participants $(36.8 \%)$ reported being extremely likely to change their pharmacy if it had low ratings in health/medicationfocused communication. The lowest percentage of older adults $(n=12,21.1 \%)$ would be extremely likely to change their pharmacy if their pharmacy reported low ratings in pharmacy staff communication (figure 2).

\section{DISCUSSION}

This study showed that older adults perceive the CEPSS as important in evaluating and comparing pharmacies. Pharmacy quality information based on the CEPSS is likely to influence older adults' pharmacy selection in 
Table 4 Older adults' perceived importance of the Consumer Experience with Pharmacy Services Survey (CEPSS)

\begin{tabular}{ll}
\hline Objective & Perceptions \\
\hline Importance of the & $\begin{array}{l}\text { The CEPSS may help in } \\
\text { avoiding worst providers and } \\
\text { choosing the best pharmacies. }\end{array}$
\end{tabular}

\section{Sample quotations}

"It rules out the worst case scenarios for you. If you've got eight to pick from, I would go with the top three...I wouldn't do the one that has poor, poor, poor, on the categories so that way at least you can narrow the field down."

The quality domains may confirm older adults' experience with their pharmacy.

Perceived importance of specific CEPSS domains
Health and medication-focused communication (HMC) is the most important quality domain that would prompt older adults to switch pharmacies.

HMC is important compared to other CEPSS domains.

Pharmacy staff communication (PSC) is the most important quality domain that would prompt older adults to switch pharmacies.

PSC is important compared with other CEPSS domains.
"It might change my perceptions of where l'm going...or it might confirm that I am where I want to be, however they are rated on these various things."

"I like information....and if you can't talk to me, especially about the interaction between medications, then I have no reason to go to that pharmacy."

"The reason I go to the pharmacy is to get medicine, and if I go to get my medicine, I want the communication to be perfect... I want them to tell me how long and when I should take it. I want all the information about my medication before I take it. So, I said [HMC], because it's the real reason I'm in there. I came to you for medication, I want everything explained to me."

"I'm already sick and what I put in my body-It's so important that it can change or alter me in a negative way. So, I agree with the young lady right here, because she's right you know, I'm sick. I can't get any sicker. So, I want to heal. So the health and medication-focused communication. I want to know what l'm taking. What it does to me, the side effects, how it's going to help me, whether side effects or no side effects, how long I have to take it, the longevity. Do I have to take it the rest of my life? Do I have to take it for a short period of time? And as long as it's communicated to me, I'm good to go."

"...the medication related communication. That's what you're going to the drug store for. The rest of the stuff you can put up with or find someplace else, as in written communication."

"Yeah, that for me is just essential. If I can't get my medication related questions addressed and answered by the pharmacist, the rest of that stuff doesn't even rise to the top. I can deal with a staff who doesn't communicate well...I can, you know, the rest of that, I still am at a point where I can deal with. But, if I'm not getting that communication about what's being sold to me for my health, l'm out of there."

"If you treat me with disrespect, I don't think I'm going to be a very good customer. Like I said before, I'm spending my money...I am not used to spending my money when I have to be treated like a dog!"

"It helps if the staff would greet people with a smile and courtesy at all times...If you're having a bad day and you work with this pharmacy, you really got a portion of my life in your hands. You're filling my prescription here. So don't be angry while you're filling my meds, you may throw the wrong thing in there.... it just helps to be courteous. If I'm a confused old lady and I don't understand this medicine and I'm confusing you, please call your manager and have her explain to me. Just treat that person with respect first."

"...l left my old pharmacies for the same reason as number 2 [PSC] ...I would really like to feel comfortable while I'm at a place and l'd like to know that the people know who I am and what I'm there for. Getting lost in the shuffle, I ain't down with that. If you can't talk to me and call me by name or a number or something, there's definitely going to be change."

"...I don't count on the pharmacist as the expert about my health. And, if I have a medication-related communication, I might ask the pharmacist but l'm more likely to look it up online or go through My Chart with my general practitioner. But, being treated with respect by the pharmacy staff is very important." 
Table 4 Continued

\begin{tabular}{|c|c|c|}
\hline Objective & Perceptions & Sample quotations \\
\hline & $\begin{array}{l}\text { Clarity of written information } \\
\text { (CWI) is the most important } \\
\text { quality domain that would } \\
\text { prompt older adults to switch } \\
\text { pharmacies. }\end{array}$ & $\begin{array}{l}\text { "I would want to make sure that...they have my prescriptions } \\
\text { correctly labeled and written and also that, when they give me } \\
\text { information on how to take that prescription and how it would react } \\
\text { with other medicines, you want that to be correct... it gives me an } \\
\text { understanding about my medication...you know, what shape and } \\
\text { color the pill is...." } \\
\text { "I would change just for that reason [CWI], yes, because that's } \\
\text { important to me. My medication is why l'm there in the first place. I } \\
\text { want the correct information about it. So, yes that would make me } \\
\text { change, if they didn't have that straight." }\end{array}$ \\
\hline & $\begin{array}{l}\text { Pharmacy care is the most } \\
\text { important quality domain that } \\
\text { would prompt older adults to } \\
\text { switch pharmacies. } \\
\text { Pharmacy care is important } \\
\text { compared to other CEPSS } \\
\text { domains. }\end{array}$ & $\begin{array}{l}\text { "The pharmacy care is very important for me, because with the } \\
\text { interaction [with the pharmacist] you can do other things that are } \\
\text { related to my condition and then the concern of the staff for my } \\
\text { condition; I think that pharmacy care is the most important for me." } \\
\text { "...that's [pharmacy care] going to cover everything, the care from } \\
\text { my pharmacist, my interaction with my pharmacist, everything with } \\
\text { the pharmacist is going to cover my medication, communication... if } \\
\text { that was not up to par, if that was really poor-quality low, then that } \\
\text { would cause me to go elsewhere." }\end{array}$ \\
\hline
\end{tabular}

varied circumstances. The pharmacist's communication about medicines and health is perceived as the most important domain within the CEPSS. Low ratings in this domain are also likely to influence older adults' pharmacy choice and to lead to a possible switch in pharmacy.

Older adults thought that the use of the CEPSS to evaluate and compare pharmacies had certain advantages and disadvantages. This result is consistent with research showing how patients use data from the CAHPS survey in evaluating health plans and hospitals. ${ }^{23}{ }^{24} \mathrm{In}$ the current study, some older adults supported the CEPSS because many health services were already compared in the market place and they perceived that an evaluation would have a beneficial effect on initially lowrated pharmacies. Hibbard et $a l^{28}$ showed that publicising hospital performance information led to higher quality among hospitals whose performance were initially low. Currently, there is no conclusive evidence of the effect of quality reports on improved quality of healthcare services. Schauffler and Mordavsky, ${ }^{29}$ reported that the public reporting of provider performance information did not affect patients' decisionmaking, or lead to provider competition and improved quality care. This result might vary by the type of healthcare service being received. For example, in a systematic review, it was concluded that public reporting stimulates quality improvements in hospitals. ${ }^{18}$ However, in the same review, it was reported that its effect in stimulating quality among health plans is mixed. ${ }^{18}$ Future research needs to examine whether publicly available pharmacy quality information stimulates quality improvement in ambulatory care pharmacies.

Some older adults were not supportive of using the CEPSS to evaluate pharmacies because the CEPSS is not based on quantifiable objective indicators of quality but rather on subjective information compiled from patients. Patients have been reported neither to understand ${ }^{30}$ nor to use objective quality metrics, in their healthcare decision-making. ${ }^{9} 31$ Also, no comparative pharmacy information based on objective quality metrics are presently being publicly reported to patients. Objective quality metrics like the "high-risk medication in the elderly' can be used by older adults to differentiate highquality pharmacies from low-quality pharmacies. Efforts to disseminate this information to older adults as a mechanism for them to choose quality providers when they are seeking care is needed urgently.

Older adults will use the CEPSS to avoid the worst pharmacies. In a previous study, patients stated that they were likely to use quality information to avoid poor quality providers, rather than to seek out the best quality provider. ${ }^{11}{ }^{32}$ This result has implications for older adults. Older adults use a lot of medicines and possibly need pharmacists' help with medication management. It is important to educate older adults that they need to actively seek quality care. Quality information should not only be used when they are disappointed with their current provider. The public reporting of pharmacies' CEPSS information will enhance older adults' active process of seeking high-quality pharmacies. With access to quality information, patients will be aware of the variation in the quality of pharmacies, they will increasingly become selective of the pharmacy they visit to fill their prescriptions and get their care, and pharmacies will make performance improvements to stay competitive. ${ }^{3}$

In the selection of a pharmacy, older adults would likely use the CEPSS to finalise their decision-making when choosing between several pharmacies. This is somewhat promising. Previous research shows that the 
Table 5 Older adults' perceptions of the influence of the Consumer Experience with Pharmacy Services Survey (CEPSS) in choosing/switching pharmacies

\begin{tabular}{lll}
\hline Objective Perceptions & Sample quotations
\end{tabular}

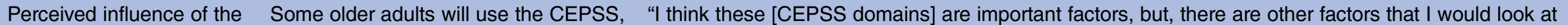
CEPSS in choosing pharmacies

Some older adults will use the CEPSS,
in addition to other factors, to choose pharmacies.

Older adults think using the CEPSS to choose pharmacies will outweigh the use of convenience.

Perceived influence of the CEPSS in switching pharmacies if current pharmacy had low ratings in domains

Some older adults would discount or ignore the low ratings of their pharmacy, placing more stock in their own experiences of their pharmacies.

Personal experience with a pharmacy may over-ride the switch of pharmacies based on the CEPSS.

Some older adults would change their pharmacies if they found their pharmacy rated low in the domains. A switch in pharmacy will only occur if there is a negative personal experience.

A switch in pharmacy will occur because the CEPSS is based on other consumers' experiences.

Some older adults would want to know why their pharmacy rated low. in choosing a pharmacy like having complaints about inaccuracy, storing prescriptions, their billing location, local variety of other items available in the store. So, this is only one group of factors l'd take in choosing a pharmacy. And there are the other factors that'd be equally or more important." "...the first one [pharmacy] that I was going to, to get my prescriptions, it was because of convenience. But then the staff wasn't as friendly and they didn't ask you questions, and then somebody recommended someplace else but it was inconvenient. But it turned out...it was worth the inconvenience, because the staff there was really concerned and I wasn't afraid to ask them questions."

"I would ignore-l'm very happy with my pharmacist and my pharmacy. And it wouldn't make any difference what the report said. I mean, I've been to different pharmacists in the past and where I'm at now they know me by name, they talk - I mean it's just a very friendly relationship, and if I saw that they had a poor rating, I would really question the people that did the study."

"I agree with 1001, l've been using this pharmacy for a number of years, it meets all these criteria, I would give it, you know, high marks on all this criteria, so I don't think I would change my use of that pharmacy."

"I probably wouldn't use [the CEPSS] because I'm happy with mine and l'd say they'd cut another tree down to write a report on stuff that is pretty obvious because you either go in there and you're happy or you're not happy and you go someplace else...experience means more than the report." "It might be down the road a little further, but l'd be looking for another pharmacy."

"Get your running shoes!"

"I don't think I would change my pharmacy unless I had a bad experience at the one I went to...a personal experience."

"I know the best information comes from my peers, the other people that are using the pharmacy...If there was a report that I knew that my peers contributed to that information and it said the pharmacy that l'm using right now is like, at the bottom of the list, l'd just leave...l'd be trying to get to the one that is at the top of the list, because I want to be treated fairly, I want to be acknowledged when I come up in there,...Some pharmacies have issues with having staff that are not as knowledgeable as others. And we don't know that. We just go there and get our prescriptions, but if I see a report that says, 'Out of 100 people, everybody says (Pharmacy name) on that corner is the best because they felt well treated...in communication they had time, the pharmacies were listening to them.'...I would definitely l'd be out of there."

"I'm going to the manager of that pharmacy and saying, 'Look, this is where you've reached, can we do something about this?' And see what the reaction is. If it's, 'Oh, we'll try to do better,' I might stay, but if they don't come up to my satisfaction or to the number one, then I leave." 


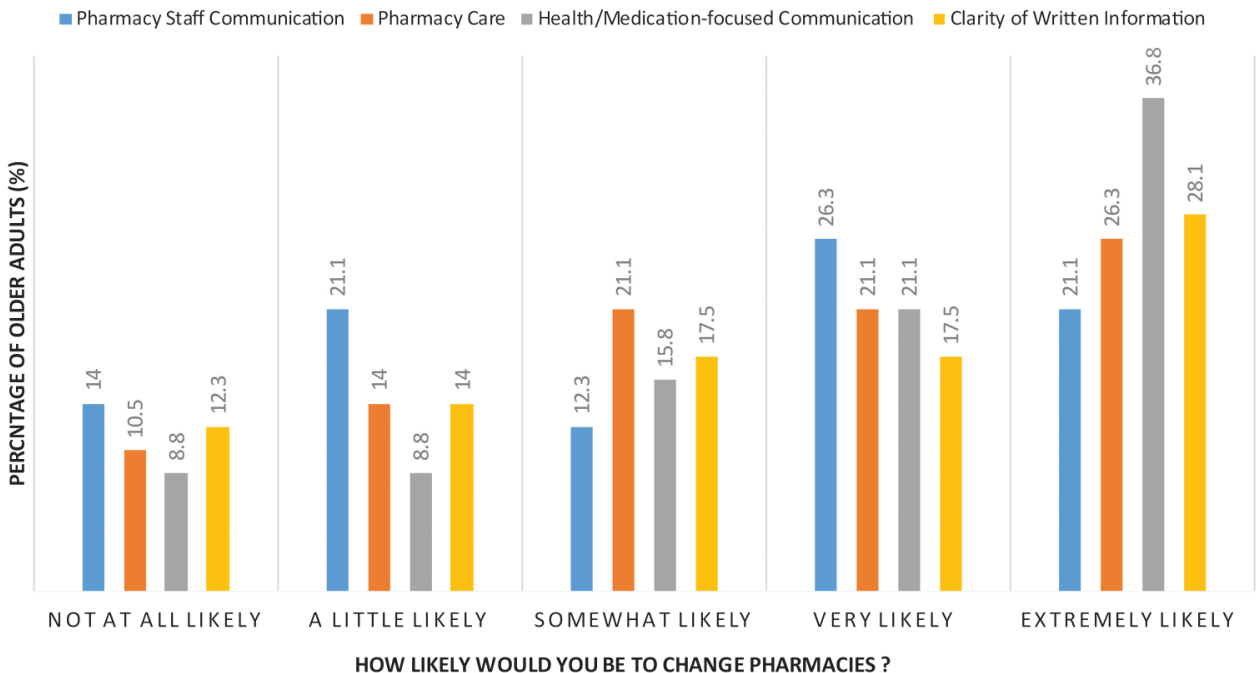

Figure 1 Older adults likelihood of changing pharmacies if pharmacy had low rating in Consumer Experience with Pharmacy Services Survey (CEPSS) quality domain ( $\mathrm{N}=57)$.

reputation of a healthcare provider, ${ }^{4}$ price $^{33}$ and family/ friends referrals ${ }^{934}$ are factors patients use in choosing a healthcare provider. Also, location and convenience have historically been important and used by patients in the initial selection of a pharmacy. ${ }^{35} 36$ However, this current study showed that when the choice of pharmacies has been narrowed down, quality information might be used in making the final decision.

Though older adults think the CEPSS is important, some participants would still rely on their personal experience rather than the survey. Specifically, some older adults preferred to use their own experience in judging quality, rather than the experience of others. This was surprising since the CEPSS is based on other patients' personal experience and one would expect older adults to actively use this information to choose their pharmacies. On the other hand, it was encouraging to know that some older adults would rely on the evaluations of their peers in changing pharmacies. Past research shows that patients value other consumers' evaluation of their healthcare experience. ${ }^{37}$ Patients like to use satisfaction measures in decision-making, especially if the responses are from people like themselves who are making similar choices. ${ }^{38}$ This finding further shows the potential value of publicly reporting pharmacy quality information based on the CEPSS. Future research should consider the appropriate format and/or content of comparative pharmacy quality information.

Older adults perceive that they would need to have a personal negative experience before they would switch their pharmacy based on the CEPSS. Patients who

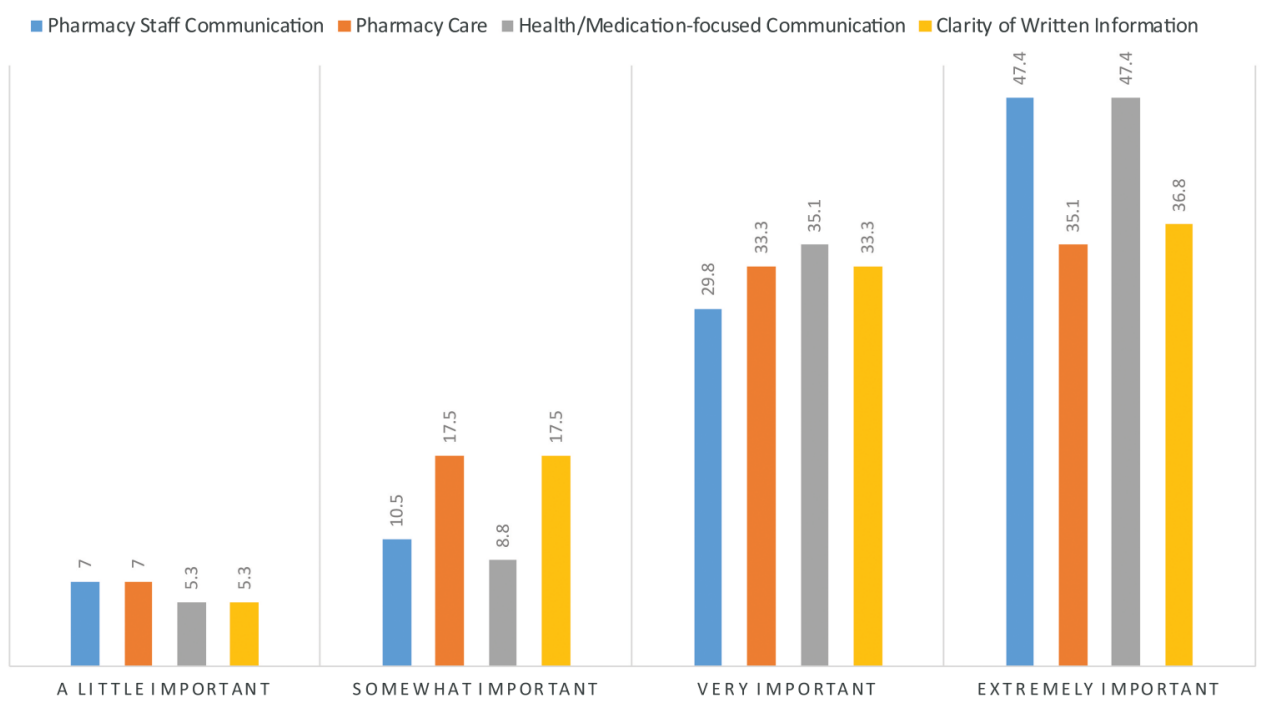

Figure 2 Older adults perceived importance of Consumer Experience with Pharmacy Services Survey (CEPSS) quality domains in evaluating and comparing pharmacies $(\mathrm{N}=57)$. 
viewed physician performance information reported the likelihood of changing physicians if he/she performed badly in a quality report. ${ }^{39}$ Previous studies have showed that when patients are satisfied with the care they receive from their healthcare provider, they become loyal and less likely to switch. ${ }^{40}{ }^{41}$ Usually, it takes having a number of bad experiences before consumers would feel dissatisfied and possibly switch their pharmacy. ${ }^{40}$ If older adults wait to have a negative experience in their pharmacy before a decision to seek a higher quality pharmacy is made, a preventable negative medication adverse effect might occur and lead to serious consequences. Owing to the multiple chronic conditions and high number of medicines used by older adults, they are more likely to need additional care from their pharmacist. Older adults are more prone to preventable adverse events and should therefore seek quality providers in their care.

The focus groups and questionnaire results from this study showed that all domains within the CEPSS were considered important. However, based on participants' questionnaire ratings, there was variability in patient perceptions of the importance of each specific CEPSS domain. The questionnaire results confirmed that health/medication-focused communication and pharmacy staff communication were the most important specific CEPSS domain. These results are not surprising. Hassel et $a l^{26}$ showed that patients use community (retail) pharmacies because they perceive the pharmacy staff to be experts on medicines, have time to talk compared with their doctors and generally are more approachable than their doctors. In a previous study of lay consumers' perception of clinical quality measures, the relationship with the pharmacist was an important factor favoured over the use of clinical quality measures in choosing a pharmacy. ${ }^{8}$ Franic et $a l^{42}$ also showed that service-related features determined the pharmacy that patients chose to fill their prescriptions. Their study results highlighted the value of the pharmacy staff and pharmacists in patients' pharmacy decision-making process. ${ }^{42}$ Using the CEPSS, pharmacies can highlight their communication skills in providing medication information, including their friendliness and caring attitudes.

Based on the questionnaire results, a pharmacy's low rating in health/medication-focused communication was extremely likely to cause a switch in pharmacy. Whitehead and colleagues observed that patients who used pharmacies with insufficient provision of medication information wanted a pharmacy with better information about medicines. These individuals were also likely to use this factor to choose their pharmacies. ${ }^{41}$ If the amount of medication information that is provided to patients is likely to influence their pharmacy choice, then it is important for pharmacies to publicise their CEPSS results as a way of increasing their patronage by other patients. The questionnaire results showed pharmacy staff communication was perceived as extremely important in evaluating pharmacies, yet a lower proportion of participants considered it extremely likely that this domain would prompt them to change pharmacies. We hypothesise that while patient-provider communication is important in enhancing patient's satisfaction with pharmacy services, patients may place a higher value in the safe administration of their medicines (reflected in their responses to the importance of health and medication-focused communication, clarity of written information, and pharmacy care) because it may be linked directly to improved health and medication use outcomes, and a reduction in medication errors.

Older adults reported that the credibility of the quality information was an important consideration in the use of CEPSS as a quality metric for pharmacies. These results are similar to a previous study of clinical pharmacy quality measures among patients with chronic illnesses. ${ }^{11}$ In addition, Hibbard et $a l \mathrm{~s}^{24}$ proposed consumer choice model has reported a lack of trust in quality information as a barrier to the use of such information in patients' decision-making. ${ }^{2}$ To enhance the use of CEPSS in patients' pharmacy choice, a credible source needs to be used in the communication of this quality information.

The older adults in this study thought that the internet, the doctor's office, AARP magazines and mass media communications were portals that could be used in disseminating pharmacy quality information. According to the consumer choice model, patients need to be aware of the availability of quality information before it can be used in their decision-making. ${ }^{24}$ Hence, the information on these possible dissemination avenues is vital to the publicising of pharmacy quality information and the use of CEPSS by older adults.

This study had some limitations. A convenience sampling approach was used in the recruitment of older adults. Our sample was predominantly female and well educated. Participants' health literacy was not addressed and will need to be examined in the future. Inter-rater reliability between the two authors who coded the data was determined by consensus and not by statistical analysis. The discussion of the CEPSS domains during the focus group might have impacted the questionnaire results. The CEPSS was developed and validated in 2007. Hence, the pharmacy services represented in the survey may not adequately represent changes in types of services increasingly offered in ambulatory pharmacy including preventative health screening, immunisation and medication therapy management services, etc. The survey may need to be revalidated prior to distribution. Also, we did not explore the question of how CEPSS data might be collected and who would pay for it.

\section{CONCLUSION}

The CEPSS may be important and influential as a quality metric in older adults' pharmacy choice. The older adults in this study would use information related 
to the pharmacist's communication about health and medicines in their decision to switch pharmacies. Pharmacies should consider using and publicly reporting CEPSS information as a means of publicising the quality of care provided to consumers.

Acknowledgements The authors would like to acknowledge the Community Academic Aging Research Network (CAARN) for helping with the recruitment of older adults into the study. The project described was supported by the Clinical and Translational Science Award (CTSA) programme, through the National Institute of Health (NIH) National Center for Advancing Translational Sciences (NCATS), grant UL1TR000427.

Contributors $00 \mathrm{~S}$ and DAM designed the study. OOS and KDC were involved in data collection and data analysis. OOS and KDC wrote the manuscript and DAM critically revised the content. All authors approved the final version of the manuscript.

Funding This research received no specific grant from any funding agency in the public, commercial or not-for-profit sector.

Disclaimer The content is solely the responsibility of the authors and does not necessarily represent the official views of the $\mathrm{NIH}$.

Competing interests None declared.

Patient consent Obtained.

Ethics approval The Education and Social/Behavioral Science Institutional Review Board of the University of Wisconsin-Madison.

Provenance and peer review Not commissioned; externally peer reviewed.

Data sharing statement No additional data are available.

Open Access This is an Open Access article distributed in accordance with the Creative Commons Attribution Non Commercial (CC BY-NC 4.0) license, which permits others to distribute, remix, adapt, build upon this work noncommercially, and license their derivative works on different terms, provided the original work is properly cited and the use is non-commercial. See: http:// creativecommons.org/licenses/by-nc/4.0/

\section{REFERENCES}

1. Marshall MN, Shekelle PG, Leatherman S, et al. The public release of performance data. JAMA 2000;283:1866.

2. Faber $M$, Bosch $M$, Wollersheim $H$, et al. Public reporting in health care: how do consumers use quality-of-care information? A systematic review. Med Care 2009;47:1-8.

3. James JA. Public Reporting on Quality and Costs Do Report Cards and Other Measures of Providers' Performance Lead to Improved Care and Better Choices by Consumers? Project HOPE: The People-to-People Health Foundation, Inc. Publication: Health Affairs/ RWJF Health Policy Briefs. http://www.rwjf.org/en/library/research/ 2012/03/public-reporting-on-quality-and-costs-.html (accessed 20 May 2016).

4. Abraham J, Sick B, Anderson J, et al. Selecting a provider: what factors influence patients' decision making? J Healthc Manag 2011;56:99.

5. Hibbard JH, Greene J, Daniel D. What is quality anyway? Performance reports that clearly communicate to consumers the meaning of quality of care. Med Care Res Rev 2010;67:275-93.

6. Yegian JM, Dardess P, Shannon M, et al. Engaged patients will need comparative physician-level quality data and information about their out-of-pocket costs. Health Affairs 2013;32:328-37.

7. Sick B, Abraham JM. Seek and ye shall find consumer search for objective health care cost and quality information. Am J Med Qual 2011;26:433-40.

8. Shiyanbola OO, Mort JR, Lyons K. Advancing the use of community pharmacy quality measures: a qualitative study. J Am Pharm Assoc (2003) 2013;53:400-7.

9. Harris K, Buntin M. Choosing a health care provider: the role of quality information. Policy 2008;1:14.

10. Shiyanbola OO, Mort JR. Exploring consumer understanding and preferences for pharmacy quality information. Pharm Pract (Granada) 2014;12:468.
11. Shiyanbola OO, Mort JR. Patients' perceived value of pharmacy quality measures: a mixed-methods study. BMJ Open 2015;5: e006086.

12. Daugherty S, Harris-Kojetin L, Squire C, et al. Maximizing the quality of cognitive interviewing data: an exploration of three approaches and their informational contributions. Paper presented at: Proceedings of the Annual Meeting of the American Statistical Association, 2001.

13. Shiyanbola OO, Mott D, Croes K. The Structural and Process Aspects of Pharmacy Quality: Older Adults' Perceptions. Int J Clin Pharm 2016;38:96-106.

14. Jordan A, McCloud R, Viswanath K. Communication and quality of care: an overview. http://jktgfoundation.org/data/ QOCInformationWhitePaper_2014July\%20FNL.pdf (accessed 20 May 2016).

15. Warholak TL ND. Quality and safety in pharmacy practice. New York, NY: Mcgraw-Hill Medical; 2010.

16. Arah OA, ten Asbroek AH, Delnoij DM, et al. Psychometric properties of the Dutch version of the hospital-level Consumer Assessment of Health Plans Survey instrument. Health Serv Res 2006;41:284-301.

17. Blalock SJ, Keller S, Nau D, et al. Development of the Consumer Assessment of Pharmacy Services survey. J Am Pharm Assoc (2003) 2011;52:324-32.

18. Fung CH, Lim YW, Mattke S, et al. Systematic review: the evidence that publishing patient care performance data improves quality of care. Ann Intern Med 2008;148:111-23.

19. Ketelaar NA, Faber MJ, Flottorp S, et al. Public release of performance data in changing the behaviour of healthcare consumers, professionals or organisations. Cochrane Database Syst Rev 2011;(11):Cd004538.

20. Spranca M, Kanouse DE, Elliott M, et al. Do consumer reports of health plan quality affect health plan selection? Health Serv Res 2000;35(5 Pt 1):933.

21. Farley DO, Elliott MN, Short PF, et al. Effect of CAHPS performance information on health plan choices by lowa Medicaid beneficiaries. Med Care Res Rev 2002;59:319-36.

22. Farley DO, Short PF, Elliott MN, et al. Effects of CAHPS health plan performance information on plan choices by New Jersey Medicaid beneficiaries. Health Serv Res 2002;37:985-1007.

23. Huppertz JW, Carlson JP. Consumers' use of HCAHPS ratings and word-of-mouth in hospital choice. Health Serv Res 2010;45:1602-13.

24. Hibbard JH, Berkman N, McCormack LA, et al. The impact of a CAHPS report on employee knowledge, beliefs, and decisions. Med Care Res Rev 2002;59:104-16.

25. Ward EC, Clark le O, Heidrich S. African American women's beliefs, coping behaviors, and barriers to seeking mental health services. Qual Health Res 2009;19:1589-601.

26. Hassel K, Rogers A, Noyce P. Community pharmacy as a primary health and self-care resource: a framework for understanding pharmacy utilization. Health Soc Care Community 1999;8:40-9.

27. Miles B, Miles A, Michael $\mathrm{H}$, et al. Qualitative data analysis: a methods sourcebook. Los Angeles: Sage, 2014.

28. Hibbard JH, Stockard J, Tusler M. Does publicizing hospital performance stimulate quality improvement efforts? Health Aff (Millwood) 2003;22:84-94.

29. Schauffler HH, Mordavsky JK. Consumer reports in health care: do they make a difference? Annu Rev Public Health 2001;22:69-89.

30. Hibbard JH, Jewett JJ. Will quality report cards help consumers? Health Aff (Millwood) 1997;16:218-28.

31. Foundation KF. 2008 update on consumers' views of patient safety and quality information. 2008. http://kff.org/health-reform/poll-finding/ 2008-update-on-consumers-views-of-patient-2/ (accessed 23 Mar 2015).

32. Arnold SB. Improving quality health care: the role of consumer engagement. Robert Wood Johnson Foundation, 2007.

33. Hibbard JH, Greene J, Sofaer S, et al. An experiment shows that a well-designed report on costs and quality can help consumers choose high-value health care. Health Aff (Millwood) 2012;31: 560-8.

34. Tu TH, Lauer JR. Word of mouth and physician referrals still drive health care provider choice. Center for Studying Health System Change, 2008.

35. Lipowski E. How consumers choose pharmacies. Am Pharm 1993 N533(12 Suppl):S14-17.

36. Franic D, Grauer DW, Law AV. An evaluation of patients' attitudes toward pharmacy selection: a determinant attribute approach. J Pharm Mark Manag 2005;17:35-50. 
37. Lubalin JS, Harris-Kojetin L. What do consumers want and need to know in making health care choices? Med Care Res Rev 1999;56:67-102.

38. Edgman-Levitan S, Cleary PD. What information do consumers want and need? Health Aff (Millwood) 1996;15:42-56.

39. Cheng S, Song H. Physician performance information and consumer choice: a survey of subjects with the freedom to choose between doctors. Qual Saf Health Care 2004; 13:98-101.
40. Oliva TA, Oliver RL, MacMillan IC. A catastrophe model for developing service satisfaction strategies. J Mark 1992;56:83-95.

41. Whitehead P, Atkin P, Krass I, et al. Patient drug information and consumer choice of pharmacy. Int $J$ Pharm Pract 1999;7:71-9.

42. Franic DM, Haddock SM, Tucker LT, et al. Pharmacy patronage: identifying key factors in the decision making process using the determinant attribute approach. J Am Pharm Assoc (2003) 2008;48:71-85. 